\title{
Prognostic significance of osteopontin expression in gastric cancer: a meta-analysis
}

\author{
Xiaobin $\mathrm{Gu}^{1}$, Xian-Shu $\mathrm{Gao}^{1}$, Mingwei Ma ${ }^{1}$, Shangbin Qin ${ }^{1}$, Xin $\mathbf{Q i}^{1}$, Xiaoying $\mathbf{L i}^{1}$, \\ Shaoqian Sun ${ }^{1}$, Hao Yu${ }^{1}$, Wen Wang ${ }^{1}$, Dong Zhou ${ }^{1}$ \\ ${ }^{1}$ Department of Radiation Oncology, Peking University First Hospital, Peking University, Beijing, China
}

Correspondence to: Xian-Shu Gao, email: doctorgaoxs@126.com

Keywords: gastric cancer, osteopontin, meta-analysis, biomarker, prognosis

Received: May 30, 2016

Accepted: September 02, 2016

Published: September 10, 2016

\section{ABSTRACT}

Background: Accumulated studies have exploited the association between osteopontin (OPN) expression and survival of patients with gastric cancer (GC), however, the results were controversial. Thus, we performed a meta-analysis, aiming to investigate the prognostic role of OPN for GC patients and to explore the association between OPN and clinicalpathological features of GC.

Results: A total of ten studies involving 1775 patients were included in final metaanalysis. Of the included studies, nine were conducted on Asian patients and one was performed on Caucasian patients. Regarding OPN detection, immunohistochemistry (IHC) was used on tissue specimens in eight studies and enzyme linked immunosorbent assay (ELISA) was used on plasma specimens in two studies. The pooled data showed that high OPN expression was correlated with poor OS (HR $=1.59,95 \% \mathrm{CI}: 1.15-2.22$, $p=0.006$ ). Subgroup analyses demonstrated that OPN had enhanced prognostic value for Asian patients $(H R=1.64,95 \% C I=1.11-2.41, p=0.012)$ and for patients receiving surgical resection $(H R=1.6,95 \% C I=1.04-2.48, p=0.034)$. In addition, the results also showed that elevated OPN expression was associated with lymph node metastasis, TNM stage, depth of invasion, tumor size and distant metastasis in GC.

Methods: Relevant studies were retrieved through PubMed, Embase and Web of Science. Combined hazard ratio (HR) and $95 \%$ confidence interval (CI) were calculated to assess the association between OPN and overall survival (OS). Subgroup analyses and publication bias were also conducted.

Conclusions: OPN overexpression was correlated with poor OS and clinical features reflecting high aggressiveness in patients with GC. OPN was a promising prognostic biomarker for GC.

\section{INTRODUCTION}

Gastric cancer (GC) is the fourth most commonly diagnosed cancer and the third leading cause of cancer related deaths among all cancer types worldwide [1]. In 2012 , there were 951,600 incident cases $(6.75 \%$ of all new cancer cases) with 723,100 deaths [2]. Although the morbidity and mortality of GC in 2012 were both slightly declined compared with those in 2008 [1], the prognosis of GC was still poor. The 5-year overall survival (OS) rate of GC is about $20 \%$ in most parts of the world [3], and prognosis is much worse for metastatic or recurrent GC than for localized disease. The median OS for metastatic $\mathrm{GC}$ is approximately one year, even when patients are treated with chemotherapy [4]. In the past several decades, various prognostic factors including $H$. pylori infection, family history, tumor stage and salt intake have been identified and been applied to aid therapeutic regimens selection, however, these parameters still lack accuracy for prediction [5]. Therefore, it is urgently needed to find novel prognostic biomarkers to provide sufficient and precise information for clinical outcomes estimation in GC.

Osteopontin (OPN) is a secreted phosphorylated glycoprotein component of the extracellular matrix (ECM). OPN mediates a variety of physiological and pathological processes including vascularization, bone resorption and tissue remodeling, atherosclerosis and autoimmune diseases. Meanwhile, OPN as a multifunctional protein 
has also been involved in every single step of cancer progression including cancer cell adhesion, tumor invasion, metastasis and angiogenesis [6-8]. Moreover, OPN was overexpressed in different solid tumors, including, but not limited to breast cancer [9], non-small cell lung cancer [10], colorectal cancer [11], hepatocellular carcinoma [12] and glioma [13]. Accumulated studies [14-23] also measured the OPN expression in primary tumor tissues or plasma in GC patients and investigated the clinical relevance between OPN and survival outcomes. However, the results of these studies were controversial and inconclusive. Therefore, we collected the most recent and relevant publications and comprehensively explored the association between OPN expression and OS as well as clinicopathological features of GC patients by using meta-analysis.

\section{RESULTS}

\section{Study selection}

Initial literature search identified 142 relevant records through above-mentioned databases. After title and abstract reading, 125 studies were eliminated. Then, seventeen full-text articles were evaluated for eligibility. Subsequently, seven studies were excluded because they lacked necessary information for meta-analysis. Finally, ten studies [14-23] published from 2007 to 2016 met the criteria for meta-analysis. The results of the search strategy were summarized in Figure 1.

\section{Characteristics of included studies}

The total number of patients was 1775 , ranging from 53 to 346 patients per study. The basic characteristics of all included studies are presented in Table 1. Nine of the ten studies were conducted in Asia [14-22] and one study [23] was performed in Italy. Regarding OPN detection, immunohistochemistry (IHC) was used in eight studies $[14,15,17-21,23]$ and enzyme linked immunosorbent assay (ELISA) was used in two studies [16, 22]. Studies using IHC detected OPN expression in primary tumor tissues $[14,15,17-22]$ and studies using ELISA measured OPN in plasma[16, 23]. For GC treatment, eight studies [14-21] used surgical resection, one study [22] used chemotherapy and one study [23] exploited surgical resection and chemotherapy. For clinical outcomes analyses, eight studies [14-16, 19-23] investigated both the association between OPN and overall survival (OS) and clinical features, while two studies $[17,18]$ only exploited the correlation between OPN and clinical factors of GC patients. The NOS scores of included studies were from 7 to 9 .

\section{OPN expression and overall survival of gastric cancer}

There were eight studies [14-16, 19-23] explored the relationship between OPN expression and OS of GC patients. Overall, high OPN expression was associated with poor $\mathrm{OS}$ in patients with $\mathrm{GC}(\mathrm{HR}=1.59,95 \%$ CI: $1.15-2.22, p=0.006$; Figure 2), although obvious

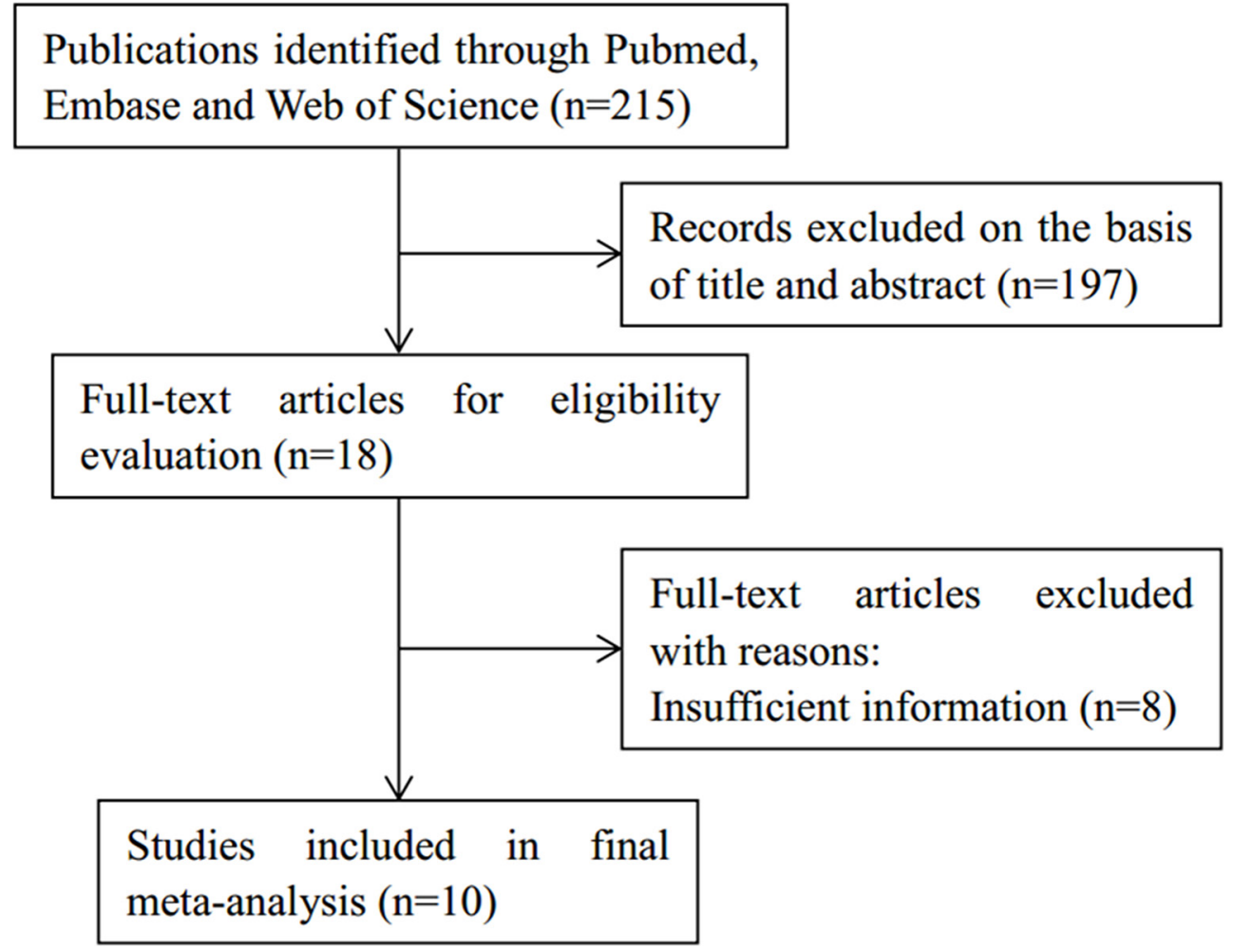

Figure 1: Study selection flow chart. 
Table 1: Characteristics of studies included in the meta-analysis

\begin{tabular}{|c|c|c|c|c|c|c|c|c|c|c|c|c|c|c|}
\hline Author & Year & $\begin{array}{l}\text { Study } \\
\text { region }\end{array}$ & Ethnicity & $\begin{array}{c}\text { No. of } \\
\text { patients }\end{array}$ & $\begin{array}{c}\text { Gender } \\
(\mathrm{M} / \mathrm{F})\end{array}$ & $\begin{array}{c}\text { Tumor } \\
\text { stage }\end{array}$ & Treatment & $\begin{array}{c}\text { Sample } \\
\text { source }\end{array}$ & $\begin{array}{c}\text { Detection } \\
\text { method }\end{array}$ & $\begin{array}{c}\text { Cut-off } \\
\text { level }\end{array}$ & $\begin{array}{c}\text { OPN + } \\
\text { n (\%) }\end{array}$ & $\begin{array}{c}\text { Follow-up } \\
\text { (month) }\end{array}$ & $\begin{array}{l}\text { Study } \\
\text { design }\end{array}$ & $\begin{array}{l}\text { NOS } \\
\text { score }\end{array}$ \\
\hline Dai & 2007 & China & Asian & 306 & $205 / 101$ & I-IV & Surgery & Tissue & IHC & $>5 \%$ & $132(43.1)$ & $32(2-120)$ & $\mathrm{R}$ & 7 \\
\hline Higashiyama & 2007 & Japan & Asian & 295 & $197 / 98$ & I-IV & Surgery & Tissue & $\mathrm{IHC}$ & $>1+$ & $205(69.5)$ & $46(2-151)$ & $\mathrm{R}$ & 8 \\
\hline Wu & 2007 & Taiwan & Asian & 132 & $86 / 46$ & I-IV & Surgery & Plasma & ELISA & $>67.3 \mathrm{ng} / \mathrm{ml}$ & $76(57.6)$ & 60 & $\mathrm{P}$ & 8 \\
\hline Tang & 2008 & China & Asian & 53 & $38 / 15$ & I-IV & Surgery & Tissue & IHC & $>$ score 0 & $40(75.5)$ & $24.7(1-51)$ & $\mathrm{R}$ & 9 \\
\hline Imano & 2009 & Japan & Asian & 85 & $59 / 26$ & I-IV & Surgery & Tissue & $\mathrm{IHC}$ & $>1+$ & $37(43.5)$ & NA & $\mathrm{R}$ & 7 \\
\hline Kim & 2009 & Korea & Asian & 211 & $138 / 73$ & I-IV & Surgery & Tissue & IHC & $>$ score 3 & $129(61.7)$ & $137(41.6-172.1)$ & $\mathrm{R}$ & 7 \\
\hline Zhang & 2009 & Japan & Asian & 109 & $63 / 46$ & I-IV & Surgery & Tissue & $\mathrm{IHC}$ & $>10 \%$ & $51(46.8)$ & $4-96$ & $\mathrm{R}$ & 8 \\
\hline Lin & 2015 & Taiwan & Asian & 170 & $97 / 73$ & I-IV & Surgery & Tissue & $\mathrm{IHC}$ & $>50 \%$ & $91(53.5)$ & 42.4 & $\mathrm{R}$ & 7 \\
\hline Ock & 2015 & Korea & Asian & 68 & $42 / 26$ & IV & Chemotherapy & \begin{tabular}{|l|} 
Plasma \\
\end{tabular} & ELISA & $>4.4 \mathrm{pg} / \mathrm{ml}$ & $34(50)$ & $81.6(32.6-113)$ & $\mathrm{R}$ & 9 \\
\hline Bartolomeo & 2016 & Italy & Caucasian & 346 & $226 / 120$ & I-III & $\begin{array}{c}\text { Surgery+ } \\
\text { chemotherapy }\end{array}$ & Tissue & $\mathrm{IHC}$ & $>1+$ & $158(45.7)$ & 60 & $\mathrm{P}$ & 8 \\
\hline
\end{tabular}

IHC:immunohistochemistry; ELISA: enzyme linked immunosorbent assay; NA: not available; R:restrospective; P: prospective; NOS: Newcastle-Ottawa Scale

heterogeneity $\left(\mathrm{I}^{2}=80.6 \%, P_{\mathrm{h}}<0.001\right)$ was found. To further investigate the prognosis role of OPN for OS in different subgroups, we conducted subgroup analysis. As shown in Table 2, OPN overexpression had enhanced capability to predicted poor OS in Asian ethnic patients $(\mathrm{HR}=1.64,95 \% \mathrm{CI}=1.11-2.41, p=0.012)$, for patients receiving surgical resection $(\mathrm{HR}=1.6,95 \%$ $\mathrm{CI}=1.04-2.48, p=0.034)$ and when ELISA was used to measure $\mathrm{OPN}(\mathrm{HR}=2.33,95 \% \mathrm{CI}=1.55-3.51$, $p<0.001)$. However, the results demonstrated that
OPN expression had no prognostic significance for patients with Caucasian ethnic background $(\mathrm{HR}=1.4$, $95 \% \mathrm{CI}=0.87-2.03, p=0.076$ ), patients receiving chemotherapy or surgery and chemotherapy treatment or when IHC was used to detect OPN. Notably, as for detection methods, OPN remained a prognostic marker by ELISA method (HR $=2.33,95 \% \mathrm{CI}=1.55-3.51$, $p<0.001$ ), and OPN was also associated with poor OS when tested by IHC, although it did not have statistical significance $(p=0.06)$.

Study

$\%$

ID

ES $(95 \% \mathrm{Cl})$

Weight

Dai (2007)

Higashiyama (2007)

Wu (2007)

Kim (2009)

Zhang (2009)

Lin (2015)

Ock (2016)

Bartolomeo (2016)

Overall $(\mathrm{I}$-squared $=80.6 \%, \mathrm{p}=0.000)$

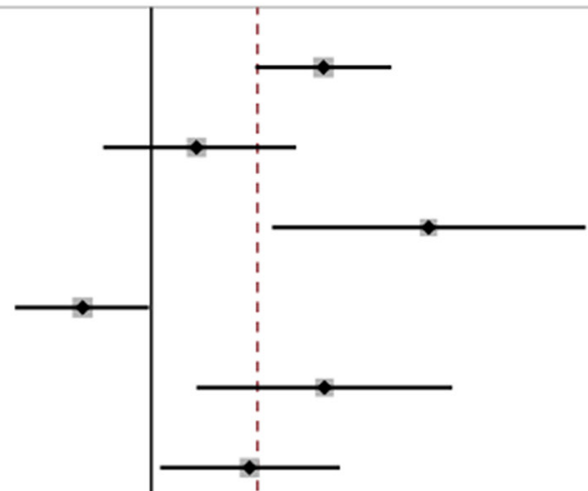

$2.13(1.58,2.87)$

14.26

$1.22(0.81,1.89) \quad 12.75$

$3.38(1.70,6.73) \quad 9.48$

$0.74(0.55,0.99) \quad 14.31$

$2.14(1.22,3.75) \quad 11.00$

$1.54(1.04,2.29) \quad 13.11$

$1.91(1.15,3.16) \quad 11.70$

$1.40(0.97,2.04) \quad 13.40$

$1.59(1.15,2.22) \quad 100.00$

NOTE: Weights are from random effects analysis

Figure 2: Forest plot of hazard ratio (HR) for overall survival of gastric cancer. 
Table 2: Association between OPN and overall survival of GC patients in meta-analysis

\begin{tabular}{|c|c|c|c|c|c|c|}
\hline \multirow{2}{*}{ Factors } & \multirow{2}{*}{$\begin{array}{c}\text { Studies } \\
\quad(n)\end{array}$} & \multirow{2}{*}{ Effects model } & \multirow{2}{*}{ HR $(95 \% C I)$} & \multirow{2}{*}{$p$} & \multicolumn{2}{|c|}{ Heterogeneity } \\
\hline & & & & & $I^{2}(\%)$ & $\mathbf{P}_{\mathrm{h}}$ \\
\hline Overall survival & 8 & Random & $1.59(1.15-2.22)$ & 0.006 & 80.6 & $<0.001$ \\
\hline \multicolumn{7}{|l|}{ Ethnicity } \\
\hline Asian & 7 & Random & $1.64(1.11-2.41)$ & 0.012 & 83.3 & $<0.001$ \\
\hline Caucasian & 1 & - & $1.4(0.97-2.03)$ & 0.076 & - & - \\
\hline \multicolumn{7}{|l|}{ Treatment } \\
\hline Surgery & 6 & Random & $1.6(1.04-2.48)$ & 0.034 & 85.6 & $<0.001$ \\
\hline Chemotherapy & 1 & - & $1.91(1.15-3.17)$ & 0.012 & - & - \\
\hline Surgery+chemotherapy & 1 & - & $1.4(0.97-2.03)$ & 0.076 & - & - \\
\hline \multicolumn{7}{|l|}{ Detection method } \\
\hline $\mathrm{IHC}$ & 6 & Random & $1.42(0.99-2.04)$ & 0.06 & 82.3 & $<0.001$ \\
\hline ELISA & 2 & Fixed & $2.33(1.55-3.51)$ & $<0.001$ & 41.8 & 0.19 \\
\hline \multicolumn{7}{|l|}{ Study design } \\
\hline Restrospective & 6 & Random & $1.49(1.01-2.2)$ & 0.046 & 83.3 & $<0.001$ \\
\hline Prospective & 2 & Random & $2.07(0.88-4.88)$ & 0.097 & 79.5 & 0.027 \\
\hline
\end{tabular}

\section{OPN expression and clinicopathological features of gastric cancer}

To further identify the impact of OPN on clinicopathological features of $\mathrm{GC}$, we investigated the correlation between OPN overexpression with ten variables including age, gender, lymph node metastasis, TNM stage, depth of invasion, tumor size, distant metastasis, tumor location, lymphatic invasion and venous invasion. The combined data showed that elevated OPN expression was associated with lymph node metastasis $(\mathrm{OR}=2.03,95 \% \mathrm{CI}=1.38-2.98$, $p<0.001)$, TNM stage (OR $=1.83,95 \% \mathrm{CI}=1.22-2.75$, $p=0.004)$, depth of invasion (OR $=1.97,95 \%$ $\mathrm{CI}=1.22-3.17, p=0.005)$, tumor size $(\mathrm{OR}=1.43$, $95 \% \mathrm{CI}=1.05-1.93, p=0.022)$ and distant metastasis $(\mathrm{OR}=2.66,95 \% \mathrm{CI}=1.24-5.71, p=0.012)$ (Table 3$)$. However, the results suggested that there was no significant association between OPN and other clinical factors, including gender, age, tumor location, lymphatic invasion and venous invasion.

\section{Publication bias}

In the present meta-analysis, using Begg's test and Egger's test, no significant publication bias was detected for the analysis between OPN and OS (Begg's $p=0.174$ and Egger's $p=0.176$; Figure 3 ). In addition, there was no significant publication bias on the analyses between OPN and clinicopathological features (Table 3). Therefore, no publication bias was found in the present meta-analysis, indicating the credibility of our study.

\section{DISCUSSION}

The involvement of OPN in carcinogenesis has been reported in the past decades, especially in promotion of tumor occurrence and metastasis [24]. More recently, it was reported that tumor-derived OPN induced mesenchymal stem cells (MSCs) to cancer-associated fibroblasts (CAFs) transformation to facilitate tumor progression and metastasis in tumor microenvironment [25]. Owing to its pivotal function in pathophysiology of cancer, OPN has been suggested as a novel and promising biomarker for cancer prognosis as well as a therapeutic target in various cancers $[26,27]$. However, the prognostic role of OPN for GC was still controversial based on previous reports.

In the present meta-analysis, we included 1775 GC patients from ten studies. The pooled HR and 95\% CI suggested that OPN predicted shorter OS in GC, especially for Asian patients and for those who received surgery. Furthermore, through the analyses of association between OPN and clinical features, we found that high OPN expression was more tightly correlated with variables which reflected the aggressiveness and dissemination of this disease including lymph node metastasis, TNM stage, depth of invasion, tumor size and distant metastasis. These results demonstrate that OPN overexpression can be considered and validated as a useful prognostic biomarker and an indicator which represents the invasiveness of gastric cancer. To the best of our knowledge, this is the first meta-analysis to date investigating the prognostic value of OPN in patients with GC.

Previous evidence showed that OPN was a stimulator in tumor progression [26]. Robertson et al. showed that OPN regulated the activation of c-Raf-ERK 
Table 3: Association between OPN expression and clinical characteristics of GC

\begin{tabular}{|c|c|c|c|c|c|c|c|c|}
\hline \multirow{2}{*}{ Features } & \multirow{2}{*}{$\begin{array}{l}\text { Studies } \\
(n)\end{array}$} & \multirow{2}{*}{$\begin{array}{l}\text { Effects } \\
\text { model }\end{array}$} & \multirow{2}{*}{ OR $(95 \% C I)$} & \multirow[b]{2}{*}{$p$} & \multicolumn{2}{|c|}{ Heterogeneity } & \multicolumn{2}{|c|}{ Publication bias } \\
\hline & & & & & $I^{2}(\%)$ & $\mathbf{P}_{\mathrm{h}}$ & Begg's p & Egger's p \\
\hline Gender (male vs. female) & 7 & Fixed & $1.11(0.88-1.41)$ & 0.378 & 42.5 & 0.107 & 1 & 0.399 \\
\hline $\begin{array}{l}\text { Lymph node metastasis } \\
\text { (yes vs. no) }\end{array}$ & 7 & Random & $2.03(1.38-2.98)$ & $<0.001$ & 54.6 & 0.04 & 0.881 & 0.415 \\
\hline TNM stage (III-IV vs. I-II) & 6 & Random & $1.83(1.22-2.75)$ & 0.004 & 51.5 & 0.067 & 0.851 & 0.504 \\
\hline $\begin{array}{l}\text { Depth of invasion } \\
\text { (T3-4 vs. T1-2) }\end{array}$ & 6 & Random & $1.97(1.22-3.17)$ & 0.005 & 57.9 & 0.037 & 1 & 0.664 \\
\hline Age $(\geq 60$ vs. $<60)$ & 5 & Fixed & $1.27(0.95-1.69)$ & 0.102 & 43.7 & 0.13 & 0.806 & 0.825 \\
\hline Tumor size $(\geq 5 \mathrm{~cm}$ vs. $<5 \mathrm{~cm})$ & 4 & Fixed & $1.43(1.05-1.93)$ & 0.022 & 31.2 & 0.225 & 1 & 0.918 \\
\hline Distant metastasis (yes vs. no) & 4 & Random & $2.66(1.24-5.71)$ & 0.012 & 55.6 & 0.08 & 0.308 & 0.193 \\
\hline $\begin{array}{l}\text { Tumor location (antrum vs. } \\
\text { cardia/fundus) }\end{array}$ & 3 & Fixed & $1.03(0.72-1.45)$ & 0.887 & 29.1 & 0.244 & 1 & 0.891 \\
\hline $\begin{array}{l}\text { Lymphatic invasion (yes vs. } \\
\text { no) }\end{array}$ & 3 & Random & $2.39(0.66-8.69)$ & 0.184 & 87.2 & $<0.001$ & 0.296 & 0.256 \\
\hline Venous invasion (yes vs. no) & 3 & Random & $1.04(0.24-4.56)$ & 0.962 & 87.9 & $<0.001$ & 1 & 0.959 \\
\hline
\end{tabular}
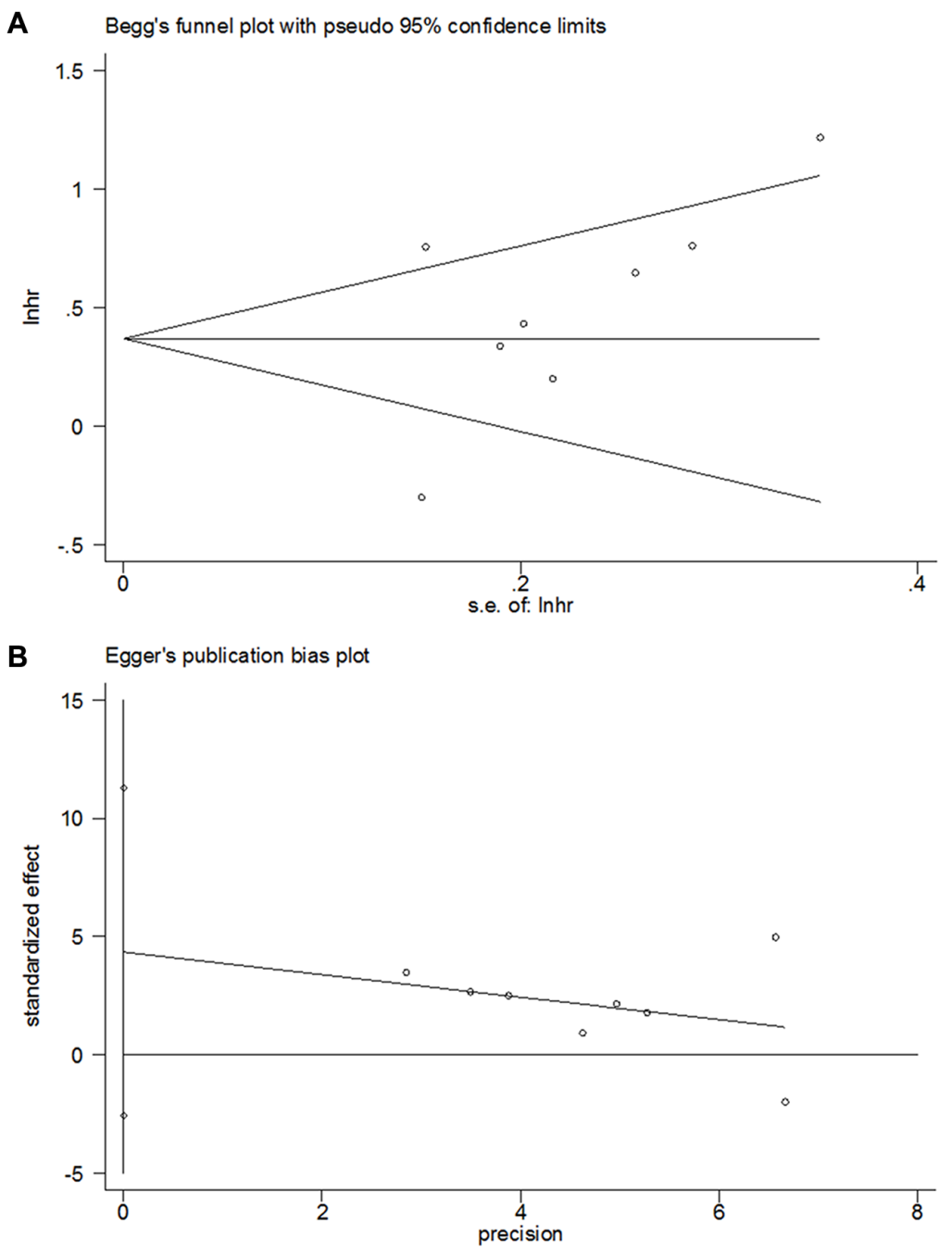

Figure 3: Publication bias for the prognostic value of OPN expression in gastric cancer by (A) Begg's test $(p=0.174)$ and (B) Egger's test $(p=0.176)$. 
cascade and OPN signaling mediated anti-apoptotic activity [28]. Chakraborty et al. demonstrated that OPN could upregulate VEGF expression and promote tumor angiogenesis in breast cancer [29]. In addition, recent studies indicated that OPN also had an immunosuppressive role in tumor milieu. Kim et al. reported that tumorderived OPN could lead to accumulation of peripheral myeloid-derived suppressor cells (MDSC), which were potent immunosuppressive cells [30]. These diverse mechanisms could potentially account for the results that OPN was associated with tumor aggressiveness in this meta-analysis.

We found several previously published metaanalyses also explored the prognostic significance of OPN in different cancers including breast cancer [31], colorectal cancer [32], non-small-cell lung cancer [33] and glioma [34]. Xu et al. showed that OPN expression was a predictor for poor overall survival and disease-free survival in breast cancer patients [31]. Zhao et al. found that OPN expression was higher in patients with highgrade glioma than patients with low grade glioma [34]. These results from other cancer types were in accordance with findings in our meta-analysis in gastric cancer, which stressed the rationale of recommending OPN as a biomarker for GC patients. Interestingly, we found that OPN was still a significant marker for OS when tested by ELISA, and was almost a significant indicator when used IHC ( $p=0.06)$. This result could be caused by the small sample size in IHC detection subgroup, more eligible studies using IHC method could possibly make the pooled results significant.

Although this is the first meta-analysis exploring the prognostic role of OPN for GC, several limitations still need to be stated. First, because we only included full papers in English, selection bias could be possible. Second, heterogeneity was found in the meta-analysis. Although we picked up eligible studies using uniform selection criteria, the difference such study design, patients, OPN detection methods still existed in the included studies, which could be the source of heterogeneity. Third, the sample size was relatively small, because only ten studies were included. Fourth, most patients in this meta-analysis were Asian ethnicities; therefore, the results may be more applicable for Asian populations. As a result, more studies on non-Asian patients are needed.

In summary, the present meta-analysis demonstrated that OPN overexpression was correlated with poor OS in patients with GC and OPN had enhance prognostic value for Asian patients and those underwent surgical resection. Moreover, OPN was associated with clinical features reflecting high aggressiveness of GC. Our results indicated that OPN was a promising prognostic biomarker for GC, which might be more applicable for Asian patients. Due to the limitations of this study, large scale studies with strict study design are still warranted to verify our results.

\section{MATERIALS AND METHODS}

\section{Search strategy}

A thorough literature search was conducted on the electronic platforms of Pubmed, Embase and Web of Science until August 16, 2016. The search strategy included items for 'OPN' (e.g. "OPN", "osteopontin", "sialoprotein 1", "secreted phosphoprotein 1", "bone sialoprotein 1") and 'gastric cancer' (e.g. "stomach neoplasms"(MeSH Terms), "GC", "gastric carcinoma", "gastric neoplasm"). Appropriate references of the retrieved studies were also manually reviewed to identify potential inclusions.

\section{Inclusion and exclusion criteria}

Studies meeting the following criteria were included: (1) patients were pathologically diagnosed as gastric cancer; (2) the OPN expression was detected by any approach; (3) study population was classified as high and low OPN expression for analysis; (4) studies investigated the association between OPN expression and survival outcomes or clinical features; (5) the hazard ration(HR) and $95 \%$ confidence interval (CI) were directly reported or can be calculated based on the information in the paper ; (6) studies must be published as original articles in English.

Studies were excluded for the following reasons: (1) reviews, letters, comments or meeting abstracts; (2) animal studies; (3) studies lacked sufficient data to extract HRs and 95\% CIs.

\section{Data extraction and quality evaluation}

Two investigators (XB Gu and $\mathrm{XS} \mathrm{Gao}$ ) read the eligible studies and extracted data independently. Discrepancies were resolved by discussion. The extracted information included: first author's name, year of publication, patients' number, country, tumor stage, treatment information, sample source, detection method, cut-off level, follow-up information and HRs with $95 \%$ CIs. The qualities of the included studies were assessed by Newcastle-Ottawa Scale (NOS) [35], and studies with $\geq 7$ scores were considered as high quality studies.

\section{Statistical analysis}

Pooled HR and 95\% CI were calculated to measure the impact of OPN expression on survival of gastric cancer patients. Heterogeneity among studies was evaluated by using a $\chi^{2}$-based Cochran $Q$ test and Higgins $\mathrm{I}^{2}$ statistic. $P$ value for heterogeneity $\left(P_{\mathrm{h}}\right)<0.10$ or $\mathrm{I}^{2}>50 \%$ was considered as significant heterogeneity, accordingly, a random-effect model (DerSimonian-Laird method) was used, otherwise, a 
fixed-effect model (Mantel-Haenszel method) was used. ORs (odds ratios) with 95\% CIs were selected to determine the association between OPN expression and clinicopathological variables of GC, such as TNM stage, lymph node metastasis, tumor size and venous invasion. The impact of OPN overexpression on survival or clinicopathological features was regarded as statistically significant if the $95 \%$ CI did not overlap with 1 . Potential publication bias was examined by using both Begg's test and Egger's test. A $p$-value $<0.05$ was considered as statistically significant. All analyses were carried out using STATA 12.0 software (Stata Corporation, Collage Station, Texas, USA).

\section{CONFLICTS OF INTEREST}

The authors confirm that there are no conflicts of interest.

\section{GRANT SUPPORT}

This work was supported by a grant from the Clinical Features Research of Capital (No. Z141107002514160).

\section{REFERENCES}

1. Piazuelo MB, Correa P. Gastric cancer: Overview. Colomb Medica. 2013; 44:192-201.

2. Torre LA, Bray F, Siegel RL, Ferlay J, Lortet-Tieulent J, Jemal A. Global Cancer Statistics. 2012. CA Cancer J Clin. 2015; 65:87-108.

3. Karimi P, Islami F, Anandasabapathy S, Freedman ND, Kamangar F. Gastric Cancer: Descriptive Epidemiology, Risk Factors, Screening, and Prevention. Cancer Epidemiol Biomarkers Prev. 2014; 23:700-713.

4. Bittoni A, Maccaroni E, Scartozzi M, Berardi R, Cascinu S. Chemotherapy for locally advanced and metastatic gastric cancer: state of the art and future perspectives. Eur Rev Med Pharmacol Sci. 2010; 14:309-314.

5. Guggenheim DE, Shah MA. Gastric cancer epidemiology and risk factors. J Surg Oncol. 2013; 107:230-236.

6. Rangaswami H, Bulbule A, Kundu GC. Osteopontin: role in cell signaling and cancer progression. Trends Cell Biol. 2006; 16:79-87.

7. Matusan-Ilijas K, Behrem S, Jonjic N, Zarkovic K, Lucin K. Osteopontin expression correlates with angiogenesis and survival in malignant astrocytoma. Pathol Oncol Res. 2008; 14:293-298.

8. Wai PY, Kuo PC. The role of osteopontin in tumor metastasis. J Surg Res. 2004; 121:228-241.

9. Singhal H, Bautista DS, Tonkin KS, O’Malley FP, Tuck AB, Chambers AF, Harris JF. Elevated plasma osteopontin in metastatic breast cancer associated with increased tumor burden and decreased survival. Clin Cancer Res. 1997; 3:605-611.
10. Takenaka M, Hanagiri T, Shinohara S, Yasuda M, Chikaishi Y, Oka S, Shimokawa H, Nagata Y, Nakagawa M, Uramoto H, So T, Yamada S, Tanaka F. Serum level of osteopontin as a prognostic factor in patients who underwent surgical resection for non-small-cell lung cancer. Clin Lung Cancer. 2013; 14:288-294.

11. Sun L, Pan J, Peng L, Fang L, Zhao X, Sun L, Yang Z, Ran Y. Combination of haptoglobin and osteopontin could predict colorectal cancer hepatic metastasis. Ann Surg Oncol. 2012; 19:2411-2419.

12. Sieghart W, Wang X, Schmid K, Pinter M, Konig F, Bodingbauer M, Wrba F, Rasoul-Rockenschaub S, PeckRadosavljevic M. Osteopontin expression predicts overall survival after liver transplantation for hepatocellular carcinoma in patients beyond the Milan criteria. J Hepatol. 2011; 54:89-97.

13. Tsai WC, Lee HS, Lin CK, Chen A, Nieh S, Ma HI. The association of osteopontin and LMX1A expression with World Health Organization grade in meningiomas and gliomas. Histopathology. 2012; 61:844-856.

14. Dai N, Bao Q, Lu A, Li J. Protein expression of osteopontin in tumor tissues is an independent prognostic indicator in gastric cancer. Oncology. 2007; 72:89-96.

15. Higashiyama M, Ito T, Tanaka E, Shimada Y. Prognostic significance of osteopontin expression in human gastric carcinoma. Ann Surg Oncol. 2007; 14:3419-3427.

16. Wu CY, Wu MS, Chiang EP, Wu CC, Chen YJ, Chen CJ, Chi NH, Chen GH, Lin JT. Elevated plasma osteopontin associated with gastric cancer development, invasion and survival. Gut. 2007; 56:782-789.

17. Tang H, Wang J, Bai F, Zhai H, Gao J, Hong L, Xie H, Zhang F, Lan M, Yao W, Liu J, Wu K, Fan D. Positive correlation of osteopontin, cyclooxygenase-2 and vascular endothelial growth factor in gastric cancer. Cancer Invest. 2008; 26:60-67.

18. Imano M, Satou T, Itoh T, Sakai K, Ishimaru E, Yasuda A, Peng YF, Shinkai M, Akai F, Yasuda T, Imamoto H, Okuno K, Ito $\mathrm{H}$, et al. Immunohistochemical expression of osteopontin in gastric cancer. J Gastrointest Surg. 2009; 13:1577-1582.

19. Kim JY, Bae BN, Kim KS, Shin E, Park K. Osteopontin, CD44, and NFkappaB expression in gastric adenocarcinoma. Cancer Res Treat. 2009; 41:29-35.

20. Zhang X, Tsukamoto T, Mizoshita T, Ban H, Suzuki H, Toyoda T, Tatematsu M. Expression of osteopontin and CDX2: indications of phenotypes and prognosis in advanced gastric cancer. Oncol Rep. 2009; 21:609-613.

21. Lin CN, Wang CJ, Chao YJ, Lai MD, Shan YS. The significance of the co-existence of osteopontin and tumorassociated macrophages in gastric cancer progression. BMC Cancer. 2015; 15:128.

22. Ock CY, Nam AR, Bang JH, Kim TY, Lee KH, Han SW, Im SA, Kim TY, Bang YJ, Oh DY. Signature of cytokines and angiogenic factors (CAFs) defines a clinically distinct subgroup of gastric cancer. Gastric Cancer. 2015; doi: 10.1007/s10120-015-0583-z. 
23. Di Bartolomeo M, Pietrantonio F, Pellegrinelli A, Martinetti A, Mariani L, Daidone MG, Bajetta E, Pelosi G, de Braud F, Floriani I, Miceli R. Osteopontin, E-cadherin, and beta-catenin expression as prognostic biomarkers in patients with radically resected gastric cancer. Gastric Cancer. 2016; 19:412-420.

24. Cao DX, Li ZJ, Jiang XO, Lum YL, Khin E, Lee NP, $\mathrm{Wu}$ GH, Luk JM. Osteopontin as potential biomarker and therapeutic target in gastric and liver cancers. World J Gastroenterol. 2012; 18:3923-3930.

25. Weber CE, Kothari AN, Wai PY, Li NY, Driver J, Zapf MAC, Franzen CA, Gupta GN, Osipo C, Zlobin A, Syn WK, Zhang J, Kuo PC, et al. Osteopontin mediates an MZF1-TGF-beta 1-dependent transformation of mesenchymal stem cells into cancer-associated fibroblasts in breast cancer. Oncogene. 2015; 34:4821-4833.

26. Shevde LA, Samant RS. Role of osteopontin in the pathophysiology of cancer. Matrix Biol. 2014; 37:131-141.

27. Bandopadhyay M, Bulbule A, Butti R, Chakraborty G, Ghorpade P, Ghosh P, Gorain M, Kale S, Kumar D, Kumar S, Totakura KVS, Roy G, Sharma P, et al. Osteopontin as a therapeutic target for cancer. Expert Opin Ther Targets. 2014; 18:883-895.

28. Robertson BW, Bonsal L, Chellaiah MA. Regulation of Erk1/2 activation by osteopontin in PC3 human prostate cancer cells. Mol Cancer. 2010; 9:260.
29. Chakraborty G, Jain S, Kundu GC. Osteopontin promotes vascular endothelial growth factor-dependent breast tumor growth and angiogenesis via autocrine and paracrine mechanisms. Cancer Res. 2008; 68:152-161.

30. Kim EK, Jeon I, Seo H, Park YJ, Song B, Lee KA, Jang Y, Chung Y, Kang CY. Tumor-Derived Osteopontin Suppresses Antitumor Immunity by Promoting Extramedullary Myelopoiesis. Cancer Res. 2014; 74:6705-6716.

31. Xu YY, Zhang YY, Lu WF, Mi YJ, Chen YQ. Prognostic value of osteopontin expression in breast cancer: A metaanalysis. Mol Clin Oncol. 2015; 3:357-362.

32. Zhao M, Liang F, Zhang B, Yan W, Zhang J. The impact of osteopontin on prognosis and clinicopathology of colorectal cancer patients: a systematic meta-analysis. Sci Rep. 2015; 5:12713.

33. Zou XL, Wang C, Liu KE, Nie W, Ding ZY. Prognostic significance of osteopontin expression in non-small-cell lung cancer: A meta-analysis. Mol Clin Oncol. 2015; 3:633-638.

34. Zhao M, Xu H, Liang F, He J, Zhang J. Association of osteopontin expression with the prognosis of glioma patient: a meta-analysis. Tumour Biol. 2015; 36:429-436.

35. Stang A. Critical evaluation of the Newcastle-Ottawa scale for the assessment of the quality of nonrandomized studies in meta-analyses. Eur J Epidemiol. 2010; 25:603-605. 